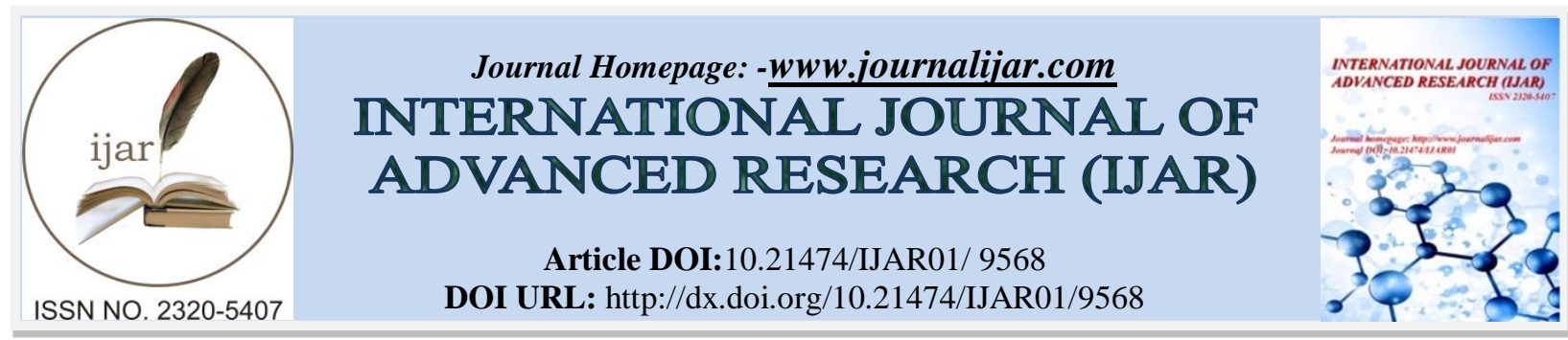

RESEARCH ARTICLE

\title{
CORRECTION OF EXCESSIVE GINGIVAL DISPLAY IN HYPERDIVERGENT SKELETAL CLASS II: A CASE REPORT.
}

\section{Dr. Fehmi mian ${ }^{1}$, Dr. Mohd Tariq ${ }^{2}$ and Dr. Yumna Qamar ${ }^{3}$.}

1. Junior resident, ziauddin ahmed dental college, Aligarh muslim university, Aligarh.

2. Professor, Department of orthodontics and dentofacial orthopaedics, Ziauddin ahmed dental college, Aligarh muslim university,Aligarh.

\section{Manuscript Info}

Manuscript History

Received: 12 June 2019

Final Accepted: 14 July 2019

Published: August 2019

Key words:-

Hyperdivergent, gingival display, miniimplants.

\begin{abstract}
Case report of a 13-year-old female patient who presented with Skeletal class II pattern with hyperdivergent growth pattern, excessive display of gingiva and proclined and protruded incisors. The objectives was proper diagnosis and management of the case for adequate control of hyperdivergent pattern and correction of gingival display along with improvement of facial profile. Treatment consisted in extraction of the all first bicuspids followed by fixed orthodontic appliances with preadjusted edgewise appliance. The result showed correction of the malocclusion with use of skeletal anchorage. Retention was given with removable upper retainer and a fixed one on the lower arch.
\end{abstract}

Copy Right, IJAR, 2019,. All rights reserved.

\section{Introduction:-}

One of the major concerns of a patient visiting an orthodontist office is smile and probably gummy smile is common complain encountered. Depending on the various etiologies, orthodontic, surgical, periodontal correction is required for the excessive gingival display[1]. A proper diagnosis and a specific treatment plan designed for the particular clinical situation of the gummy smile is important. The age is also an important criterion that needs to be considered[2]. Malocclusions with severely proclined anterior teeth along with excessive display of teeth are difficult to correct as they are often characterized by hyperdivergent growth pattern. [3]

Control of anchorage in antero-posterior as well as vertical direction is also an important aspect of orthodontic treatment. Although extra-oral anchorage can be used, but patients often reject the use of a headgear because of aesthetic and social concerns. To obtain anchorage without patient cooperation, endosseous implants, miniplates, mini-implants and screws have been used as orthodontic anchorage.[4-7].

In the case presented here, mini-implants were used for correction of gingival display, control of hyperdivergent pattern as well as correction of proclined and protruded upper anterior teeth.

\section{Case report}

\section{History}

A girl aged 13 years and 3 months presented at the Department of Orthodontics with the chief complaint of forwardly placed upper teeth and unattractive smile. She showed good general health with no history of trauma or serious illness. 


\section{Diagnosis and etiology}

The extra-oral clinical examination showed an apparently symmetrical mesoprosopic face with a convex profile. The patient had an incompetent, short upper lip showing marked protrusion together with everted lower lips, mentalis strain and deep labio mental sulcus. The patient had a high smile line with increased gingival display.

Intra-orally there was a Class I molar and canine relation bilaterally with an overjet of $8 \mathrm{~mm}$ and overbite of $5 \mathrm{~mm}$ (70-80\% deep bite).Moderate to severe crowding was present in the lower arch together with an exaggerated curve of Spee (Figures I).

A panoramic radiograph showed the permanent dentition stage with erupting third molar in all the quadrants. (Figure II). Cephalometric analysis revealed a skeletal Class II anterio-posterior discrepancy with an ANB angle of $6^{\circ}$. The patient had a hyperdivergent growth pattern with FMA of $28^{\circ}$. The patient had severely proclined maxillary incisors $\left(\mathrm{U} 1-\mathrm{NA} 35^{\circ}\right.$ ), the lower incisors were also protruded and proclined (IMPA98 ${ }^{\circ}$ ) (Figure II, Table I). COGS analysis showed normal upper and lower anterior facial height. Increased distance of maxillary incisors from nasal floor showed vertical anterior dental excess. The cast analysis showed a total discrepancy of $12 \mathrm{~mm}$ in the maxillary arch and a total discrepancy of $10.8 \mathrm{~mm}$ in the lower arch with a crowding of $8 \mathrm{~mm}$ and curve of spee of $2 \mathrm{~mm}$ with the headplate correction of $0.8 \mathrm{~mm}$. Functional assessment revealed that mouth opening and excursions were within normal functional limits with no signs and symptoms of a temporomandibular disorder.

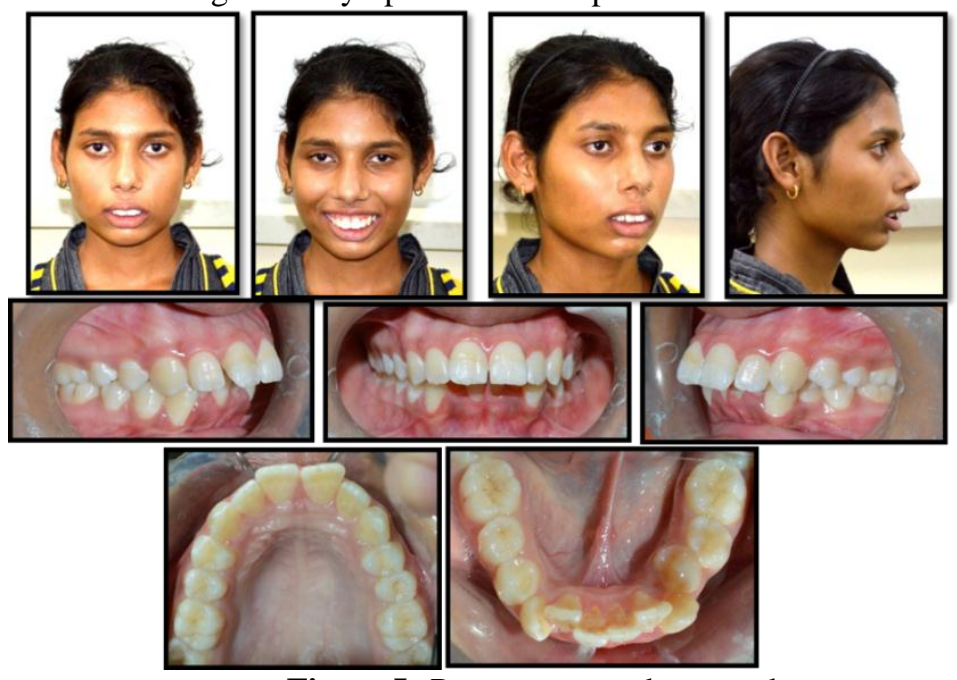

Figure I:-Pre-treatment photographs
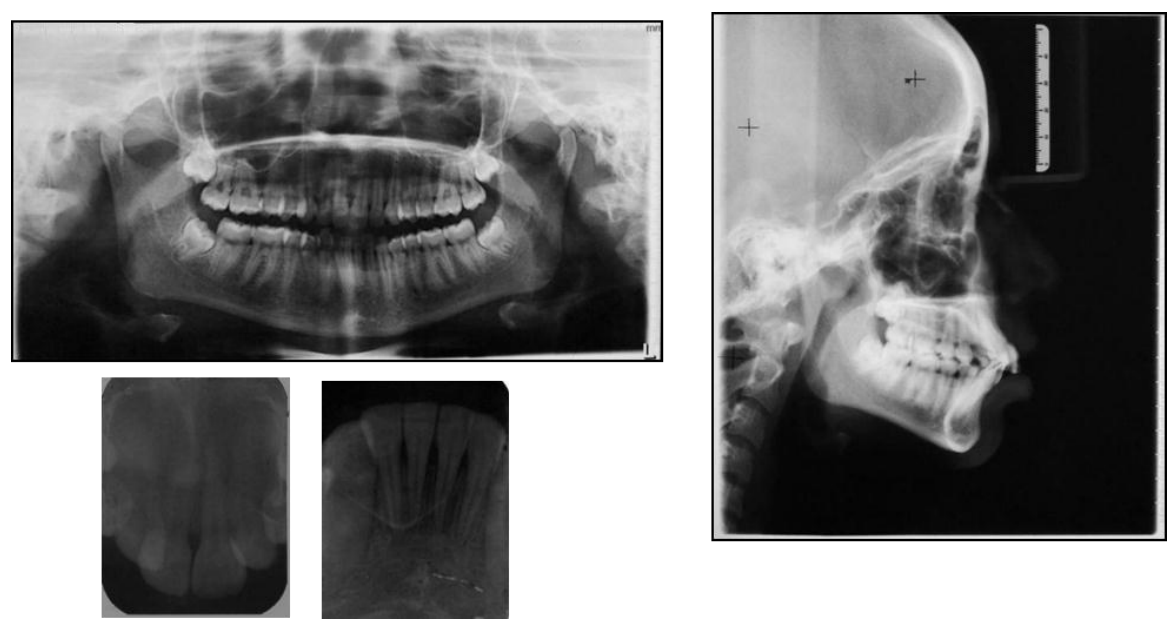

Figure II:-Pre-Treatment Radiographs 


\section{Treatment objectives}

In the maxillary dentition, the treatment objectives included control of hyperdivergent growth pattern, correction of axial inclinations of the incisors, and to eliminate lip strain on closure along with correction of nasolabial angle. Also Intrusion of upper incisors was required in the maxillary arch to correct excessive gingival display on smile. Absolute anchorage was required in the maxillary arch for retraction and intrusion of the incisors.

Treatment objectives in the mandibular arch included resolving the severe crowding, along with leveling the curve of Spee. Correction of lower incisor inclination was also required. Moderate anchorage was also planned in the mandibular arch.

Additional objectives included correction of deepbite and increased overjet.

\section{Treatment alternatives}

The treatment plan involved extraction of first premolars in the maxillary arch followed by retraction and intrusion of upper anteriors with mini-implant anchorage.

In the lower arch the treatment plan involved extraction of the first premolars followed by resolving of anterior crowding and correction of inclination of anterior teeth. The primary consideration in selecting this treatment plan was the control of vertical growth, excessive gingival display and severity of maxillary dent alveolar protrusion.

\section{Treatment progress}

The treatment was started with bonding of teeth with preadjusted edgewise appliance $(0.022 \times 0.028$ inch MBT slot). The maxillary and mandibular molars were banded. Initial alignment was achieved with 0.016-inch, 0.018 inch and 0.20 inch nickel titanium archwires followed by $0.017 \times 0.025$ inch and $0.019 \times 0.025$ inch stainless steel arch wires. The archwires were cinched in the upper arch to avoid proclining the incisors. After the alignment of the upper arch, the upper first premolars were extracted as discussed in the treatment plan. Selfdrilling mini-implants (1.3 $\mathrm{mm}$ in diameter, $8 \mathrm{~mm}$ in length) were inserted into the buccal alveolar bone between the maxillary first molar and second premolar on either side of the arch. The implants were inserted under local anesthesia using a screwdriver available with the kit. Periapical X-rays were taken for each implant to confirm that no contact was made with the roots of the adjacent teeth. A $0.019 \times 0.025$-inch stainless steel archwire with 'anterior hooks' (crimpable hooks) placed distal to lateral incisors, was inserted into the upper arch. One hundred and fifty grams of force was applied on each side for enmasse retraction of maxillary anterior teeth with a nickel titanium coil spring (closed) extending from the implant head to the hook between the lateral incisor and canine (Figure III). [12] After five months of retraction, the archwire was cut distal to the canines to increase the intrusive component on the anterior segment. Complete space closure was achieved two months later. The incisors were intruded by $3 \mathrm{~mm}$. In the lower arch after extraction of first premolars, the canines were individually retracted by active laceback. After the retraction of canine, blocked out lateral incisor was bonded. Crowding in the lower anteriors were resolved with 0.014 inch, 0.016 inch, 0.018 inch nickel titanium archwires. Lower incisor inclination was corrected in the remaining space. (Figure III). Leveling and aligning was done with continuous nickel titanium archwires. $0.019 \mathrm{X}$ .025-inch TMA archwires and cusp-seating elastics were used in the final stages of treatment. A removable Hawley retainer was placed on the maxillary teeth, and a bonded lingual retainer on the mandibular teeth. The implants were removed under topical anesthesia by unscrewing in the anticlockwise direction.
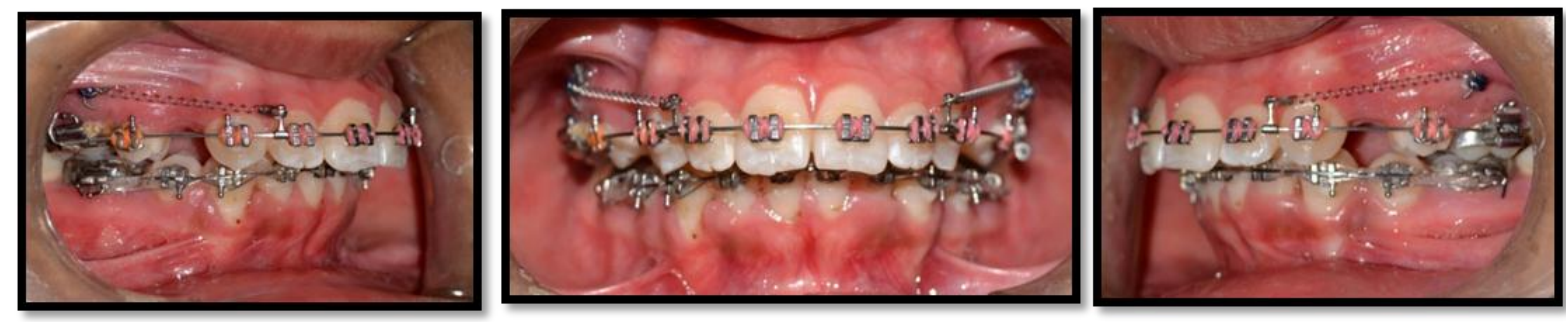

Figure III:-Treatment progress.retraction and intrusion of upper anteriors with absolute anchorage 


\section{Treatment results}

Total treatment time was 24 months. Favorable changes were observed with harmonious relationship of the facial soft tissue. The patient showed a broad symmetric smile with ideal amount of tooth structure displayed and the incisal line running along the border of the lower lip.

Intra-orally, a well-interdigitated buccal occlusion with a Class I canine and molar relation was obtained. Ideal overjet and overbite were established (Figure IV). Cephalometric radiographs and superimpositions showed $7 \mathrm{~mm}$ of maxillary incisor retraction and $3 \mathrm{~mm}$ of intrusion with titanium screw anchorage. The SNA angle was reduced by 2 degree (Figures V,VI). Post-treatment panoramic radiograph showed good root paralleling. Supporting tissues appeared healthy, and only minimal apical blunting of the upper central incisor roots was observed. The patient has been in retention for more than 15 months and the results have been maintained.
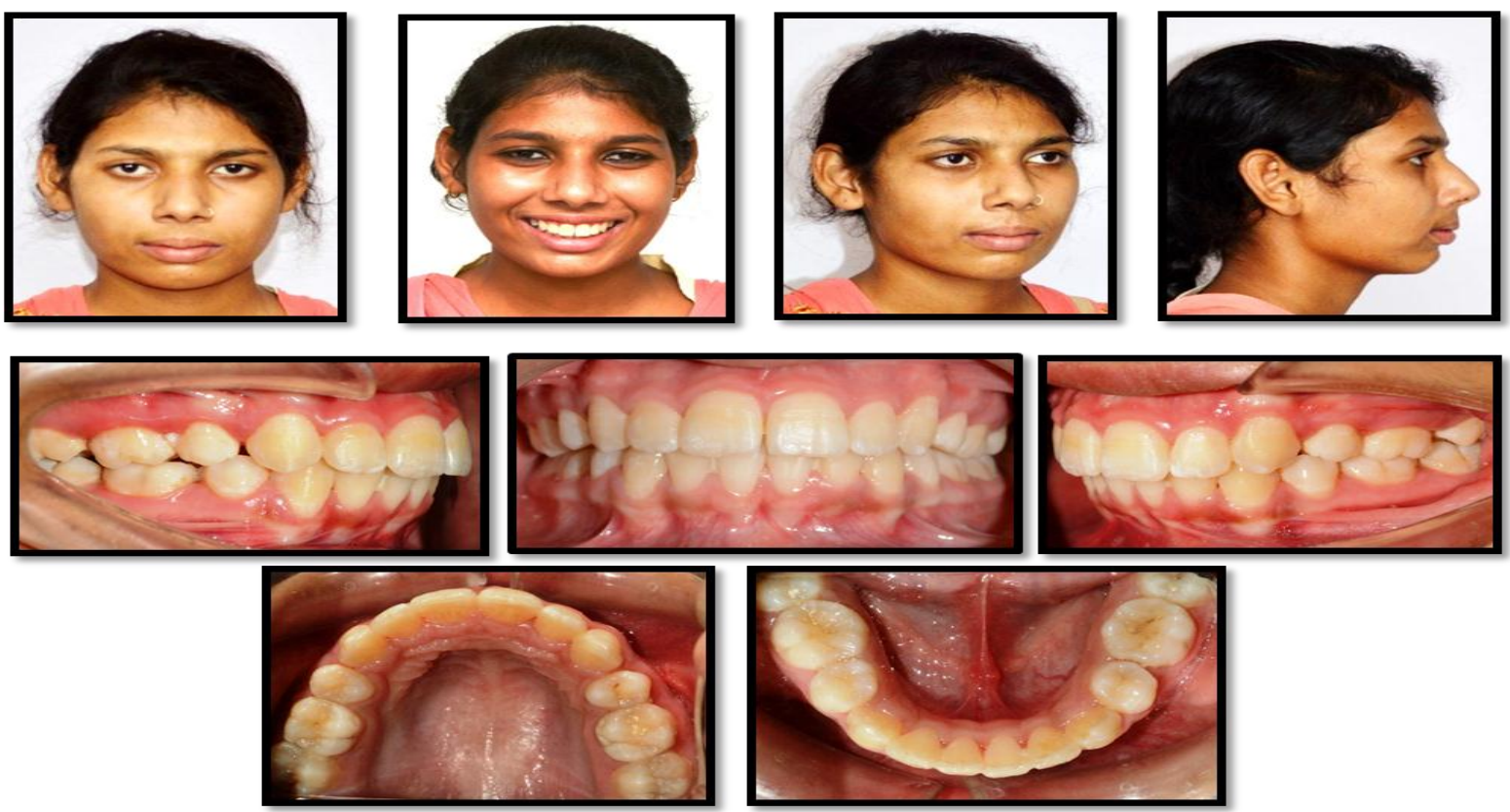

Figure IV:-Post-Treatment Photographs
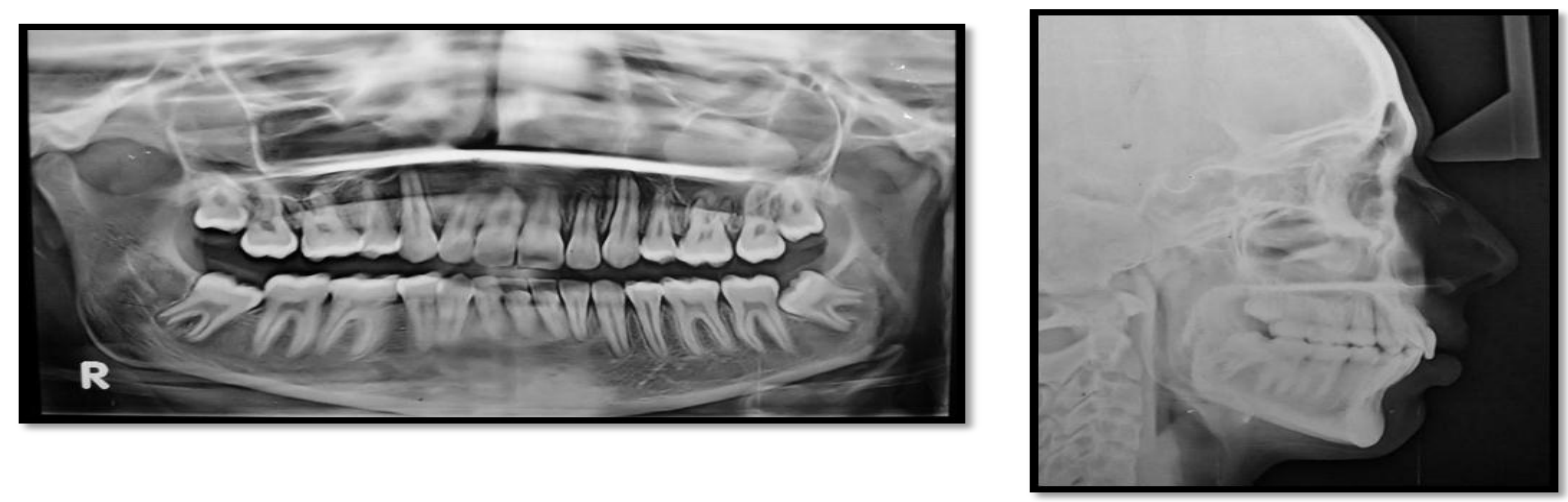

Figure V:-Post-treatment radiotographs

\section{Discussion:-}

A non-growing hyperdivergent skeletal class II case can be treated orthodontically through camouflage.the above case required adequate control of hyperdivergence along with correction of proclination and excessive gingival display. The high-angle patients can effectively controlled by controlling the vertical position of maxillary posterior region. Headgear, [8] bite-blocks, [9] and vertical-pull chincups [10] are several appliances that have been previously used to control the vertical dimension of the face during growth. However, with the advent of mini- 
implant skeletal anchorage[11], the boundaries of orthodontic treatment have been redefined, especially in adults who do not usually want to wear extraoral appliances for obvious social and esthetic reasons.

In cases of excessive display of gingiva can be skeletal, dental, soft tissue or periodontal. The gummy smile due to dental etiologies like extruded or protruded and proclined upper incisors can be managed orthodontically[1-2]. Various orthodontic procedures including auxillary arches, intrusion bends and mini-implants have been used for orthodontic correction of gingival display. Combined orthodontic and orthognathic surgical procedures are required in increased supra eruption of the upper and lower anterior teeth with thinning of the alveolar trough and prominence of roots throught he mucoosa[12].

In the above case, patient had moderate to severe anteroposterior and vertical skeletal discrepancies in conjunction with proclined upper incisors and crowded lower anteriors. The biomechanics involved in the en-masse retraction with implant-assisted anchorage have certain advantages especially in high-angle patients[13]. Throughout the retraction phase, the vertical component of the total force constantly increases because of an increase in the angulation between the applied force and the occlusal plane[15]. Consequently, these patients showed intrusion of the entire arch, with more intrusion of anteriors as compared to molars. The occlusogingival position of the miniimplant or the use of a power arm or crimpable hook can also be critical factors in defining the vertical component of the total force. [14]

\begin{tabular}{|c|c|c|c|}
\hline Measurement & Normal & Pre-treatment & post-treatment \\
\hline SNAC $\left.{ }^{-1}\right)$ & $8 z=2$ & 83 & 81 \\
\hline SNBC- & $80 \neq 2$ & 76 & $>8$ \\
\hline ANBC- & 2 & $>$ & 3 \\
\hline Noming & -4.46 & -3 & -4 \\
\hline 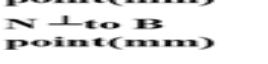 & -11.03 & -14 & -13 \\
\hline $\begin{array}{l}N 1 \cos \\
\text { posinan) }\end{array}$ & -10.5 & -13 & -12 \\
\hline FMAC - ) & $23.83 \pm 20$ & 28 & 28 \\
\hline SN-MP(-) & $32-350$ & $3 \mathbf{3}$ & 33 \\
\hline Ar-go-mer ${ }^{-1}$ & $123=70$ & 127 & 127 \\
\hline U1-NA(mm) & $4.92 \pm 2.05$ & 10 & $>$ \\
\hline U1-NA(-) & $24.02 \pm 5.820$ & 35 & 25 \\
\hline L-NBS(mm) & $6=1.7$ & 10 & $>$ \\
\hline La-NBC-) & $27 \pm 4.30$ & 30 & 24 \\
\hline IMPAC & 970 & 98 & 97 \\
\hline E-line $=U(\mathrm{~mm})$ & -4 & -1 & -3 \\
\hline Elline $=\mathrm{L}(\mathrm{mm})$ & -2 & o & -1 \\
\hline $\begin{array}{l}\text { Nasolabial } \\
\text { amblec-p }\end{array}$ & $100 \pm 6$ & 92 & 90 \\
\hline cinesine & $45 \Rightarrow 2.1$ & 40 & 40 \\
\hline${ }_{m}^{1} \bar{x}(1)$ Ne) & $30.5 \neq 2.1$ & 35 & 32 \\
\hline
\end{tabular}

Figure Vi:-Pre-Treatment And Post- Treatment Cephalometric Readings

\section{References:-}

1. Seixas MR, Costa-Pinto RA, Araújo TM. Gingival esthetics: an orthodontic and periodontal approach. Dental Press Journal of Orthodontics. 2012 Oct;17(5):190-201.Dandajena TC, Nanda RS. Bialveolar protrusion in a Zimbabwean sample. Am J Orthod Dentofacial Orthop 2003;123:133-7.

2. Zachrisson BU. Repositioning of the gingival margin by extrusion and intrusion. World J Orthod. 2003;4(1):727.

3. Klontz HA. Facial balance and harmony: an attainable objective for the patient with a high mandibular plane angle. Am J Orthod Dentofacial Orthop 1998;114:176-88.

4. S. M. Bae, H. S. Park, H. M. Kyung, O. W. Kwon, and J. H. Sung, "Clinical application of micro-implant anchorage," Journal of Clinical Orthodontics, vol. 36, no. 5, pp. 298-302, 2002

5. A. Carano, S. Velo, P. Leone, and G. Siciliani, "Clinical applications of the Miniscrew Anchorage System," Journal of Clinical Orthodontics, vol. 39, no. 1, pp. 9-24, 2005.

6. M. A. Papadopoulos and F. Tarawneh, "The use of miniscrew implants for temporary skeletal anchorage in orthodontics: a comprehensive review," Oral Surgery, Oral Medicine, Oral Pathology, Oral Radiology and Endodontology, vol. 103, no. 5, pp. e6-e15, 2007. 
7. H. S. Park, "A new protocol of the sliding mechanics with micro-implant anchorage (MIA)," Korean Journal of Orthodontics, vol. 30, pp. 677-685, 2000.

8. Majourau A, Nanda R. Biomechanical basis of vertical dimension control during rapid palatal expansion therapy. Am J Orthod Dentofacial Orthop 1996;106:322-8.

9. Kuhn RJ. Control of anterior vertical dimension and proper selection of extraoral anchorage. Angle Orthod 1968;38:340-9.

10. Vaden JL. Nonsurgical treatment of the patient with vertical discrepancy. Am J Orthod Dentofacial Orthop 1998;113:567-82.

11. H. S. Park, O. W. Kwon, and J. H. Sung, "Microscrew implant anchorage sliding mechanics," World Journal of Orthodontics, vol. 6, no. 3, pp. 265-274, 2005.

12. MOS PJ. EXCESSIVE GINGIVAL DISPLAY-A REVIEW'.

13. Prabhu J, Cousley RRJ. Current products and practice: bone anchorage devices in orthodontics. J Orthod 2006; 33: 288-307.

14. Samuels RH, Rudge SJ, Mair LH. A clinical study of space closure with nickel-titanium closed coil springs and elastic module. Am J Orthod Dentofacial Orthop 1998; 114: 73-79.

15. Hartsfield JK. Development of the vertical: nature and nurture. Semin Orthod 2002;8:113-9. 